\title{
AS FACČ̃̃ES CARIOCAS EM PERSPECTIVA COMPARATIVA
}

BENJAMIN LESSING

TRADUÇÃo: HÉLIO de MEllo Filho

\begin{abstract}
RESUMO
Entre os especialistas em segurança pública, tornou-se lugarcomum a idéia de que a guerra do tráfico no Rio de Janeiro é totalmente única no Brasil. Porém, essa afirmação é imprecisa. Organizações de narcotráfico em muitos aspectos comparáveis às facções cariocas existem em outros contextos urbanos. O que as diferencia é menos a capacidade de estabelecer o monopólio local sobre o comércio de drogas do que a resiliência da sua estrutura interna e, portanto, a duração da sua existência e dominação. Durante uma pesquisa de campo em nove comunidades de periferia de três cidades, observei não apenas uma alta variação nos graus de concentração entre os mercados locais de drogas, mas também de variação com o tempo dentro da mesma comunidade. Desta perspectiva, a estabilidade do mercado de drogas altamente concentrado do Rio de Janeiro pode ser visto como um equilíbrio único, no qual as forças de fragmentação operantes em outras cidades são neutralizadas por características específicas das facções cariocas. O meu argumento é o de que tais características decorrem do domínio exercido pelas facções sobre o sistema penitenciário desde antes do início da sua expansão para o comércio de drogas.
\end{abstract}

PALAVRAS-CHAVE: tráfico de drogas; guerra do tráfico; facções cariocas; sistema penitenciário do Rio de Janeiro.

\section{ABSTRACT}

It has become a commonplace that Rio de Janeiro's guerra do tráfico is entirely unique within Brazil. In fact, this is inaccurate. Drug trafficking organizations that in many respects resemble Rio's facções do exist in other urban contexts. What differentiates them is less the ability to establish a local monopoly on the drug trade than the resilience of their internal structure, and consequently the duration of their existence and domination. During field research in nine peripheral communities in three cities, I observed not only high variation in the degree of concentration between local drug markets, but also variation over time within single communities. In this light, the stability of Rio's highly concentrated drug market can be seen as a unique equilibrium in which the fragmentary forces at work in other cities are neutralized by specific traits of Rio's factions. These traits, I argue, stem from the dominion these factions have exerted over the state's prison system since before the period of their original expansion into the drug trade.

KEYWORDS: drug dealing; drug war; Rio de Janeiro's prisional system.

Entre os especialistas em segurança pública brasileira, é lugar-comum que a guerra do tráfico carioca é única no Brasil, sendo vista como referência de violência, corrupção e caos. Durante a realização da pesquisa de campo apresentada neste artigo, foram feitas entrevistas com autoridades policiais e civis de São Paulo, Recife e Porto Alegre sobre a estrutura do mercado de drogas em suas cidades. 
Quase sempre, cientes de que eu vivia no Rio de Janeiro, as respostas começavam com advertências deste tipo: "nós não temos aqui nada que possa ser comparado com o Rio". Por "nada", os entrevistados normalmente referiam-se às seguintes características: grandes e bem organizadas operações de vendas de droga no varejo, tipificado pelo Comando Vermelho $(\mathrm{CV})$; confrontos diretos e ataques às forças policiais; e domínio territorial das áreas de favelas com o bloqueio ao acesso da polícia. As autoridades cariocas talvez contra-argumentariam de forma perspicaz que agora São Paulo tem o seu próprio "comando" e que Recife tem a mais alta taxa de homicídios por habitante do país. Porém, apesar da propensão dos delegados locais para apresentar suas cidades como seguras, há diferenças realmente flagrantes entre o Rio e outras cidades brasileiras. Em várias dimensões, como nível de armamento, número de "soldados" armados, civis e policiais mortos em conflitos, o Rio de Janeiro nitidamente constitui uma realidade à parte.

No entanto, não é bem verdade que os mercados locais de drogas de outras cidades não tenham "nada que possa ser comparado" com os do Rio. Mesmo na pequena amostra de comunidades de baixa renda visitadas, foi possível constatar uma ampla variação em tamanho e estrutura das operações com drogas, nível de armamento, atitude diante do confronto e extensão do domínio territorial. Embora seja verdade que não exista um comércio de drogas ilícitas tão estruturado, com tanta persistência ao longo do tempo e sobre uma área tão vasta, como acontece no Rio de Janeiro, as outras cidades exibiram casos de operações locais surpreendentemente organizadas. Por outro lado, exemplos de mercados locais altamente fragmentados ou "pulverizados", praticamente inexistentes nas favelas cariocas, são abundantes nas outras cidades. Para entender melhor essa variação, convém identificar os sintomas externos da concentração do mercado de drogas. Nas entrevistas qualitativas realizadas, ficou claro que as "empresas" de tráfico escolhem suas estratégias, estruturas internas e laços com a comunidade, de forma relativamente uniforme, em função do grau de concentração do mercado de drogas do local em que operam. Com base em tais constatações, conceitualizei concentração do mercado de drogas como uma variável ordinal correlacionada com (e portanto mensurável por) aspectos pertinentes da estrutura e do comportamento das empresas de tráfico locais. A vantagem dessa abordagem é tripla. Primeiro, porque permite perceber que os mesmos sintomas da concentração do mercado aparecem (e desaparecem) em todos os locais onde drogas são vendidas, ainda que com diversos graus de freqüência e intensidade. Segundo, porque permite uma base de comparação dos mercados de drogas dentro das e entre as cidades, bem como a incorporação de observações futuras de outros estudos de caso. Por fim, por 
[1] O estudo original foi parte de um projeto de pesquisa sobre demanda por armas de fogo em vários países. Ver: Atwood, David, Glatz, Anne-Kathrin and Muggah, Robert, Demanding attention: addressing the dynamics of small arms demand. Genebra: Small Arms Survey, 2006. O Small Arms Survey é um projeto de pesquisas independente, do Instituto de Estudos Internacionais de Genebra, na Suíça.

[2] Dowdney, L. Crianças do tráfico: um estudo de caso de crianças em violência armada organizada no Rio de Janeiro. Rio de Janeiro: 7 Letras, 2003. O autor agradece ao Sr. Dowdney por sua generosidade em ceder as entrevistas para este projeto.

[3] Lessing, B., "Demanda por armas de fogo no Rio de Janeiro". In: Rubem C. Fernandes (org.). Brasil: as armas $e$ as vítimas. Rio de Janeiro: ISER/ 7 Letras, 2005. basear a medição da concentração do mercado de drogas em indicadores relacionados ao comportamento das empresas de tráfico e dos seus chefes, esta abordagem nos ajuda a identificar com mais atenção a lógica subjacente à expansão dessas empresas, e também as forças que retardam ou se contrapõem à consolidação do mercado.

Este artigo apresenta os dados de pesquisas de campo realizadas em Recife, São Paulo e Porto Alegre, em maio e junho de 2005, como parte de um projeto sobre a demanda por armas de fogo do Instituto de Estudos da Religião (ISER) e da Small Arms Survey'. Visitei eentrevistei moradores, incluindo traficantes e ex-traficantes, de nove comunidades de baixa renda, três em cada cidade, bem como oficiais de polícia, outras autoridades governamentais e representantes da sociedade civil com conhecimento direto das atividades criminosas nas respectivas comunidades. No caso do Rio, tive acesso às entrevistas originais realizadas por Luke Dowdney para o seu estudo, Crianças do tráfico², assim como outras entrevistas feitas em 2005 por mim, Jessica Galeria, e o próprio Dowdney, para o estudo "Demanda por armas de fogo no Rio de Janeiro", também do ISER. 3

Com este conjunto declaradamente limitado de observações, junto com a vantagem comparativa adquirida com o quadro apresentado acima, apresento algumas inferências provisórias sobre os mecanismos causais da situação anômala do Rio. De acordo com a análise desenvolvida, torna-se evidente que a diferença crucial entre o Rio de Janeiro e as outras cidades não reside tanto na tendência das organizações do tráfico de drogas para formar, expandir e consolidar seus territórios (o que parece ser um traço mais ou menos universal), tampouco no comportamento observado que, tudo indica, caracteriza os diferentes níveis de concentração, mas sobretudo na capacidade de os grupos cariocas resistirem e superarem as forças contrárias que levam à fragmentação dos mercados de drogas e à extinção das operações que crescem em demasia. Enquanto na maioria das cidades brasileiras tais forças resultam em um equilíbrio dinâmico, com mercados locais de drogas que variam entre níveis baixos e médios de concentração, no Rio isso não acontece. Lá, o comércio de drogas foi dominado desde cedo por grupos que tinham um traço específico: o domínio do sistema penitenciário do Estado, o que ajudou a neutralizar essas forças fragmentadoras, permitindo o estabelecimento de um equilíbrio surpreendentemente estável num nível al to de concentração.A importância desse traço, segundo o meu argumento, nem sempreé reconhecida de forma adequada pelos analistas das facções criminosas cariocas, eé preocupantemente menosprezada nas atuais discussões sobre a realidade carioca. Assim, acredito que considerar a guerra do tráfico no Rio de uma perspectiva comparativa pode propiciar uma percepção mais clara das raízes do mal-estar atual da Cidade Maravilhosa. 
O primeiro desafio ao consideraros mercados de drogas do Rio de uma perspectiva comparativa é elaborar uma escala útil, que permita a comparação com outros locais. A variável principal que proponho é a concentração do mercado de drogas. Assim como todos os mercados, o de drogas ilícitas pode ser caracterizado pelo grau de concentração ou fragmentação, ou seja, o grau de controle exercido por "empresas" sobre porções significativas ou dominantes do mercado. O intervalo teórico de níveis de concentração de mercado varia desde a concorrência perfeita até o monopólio. Em mercados locais — ou seja, no nível de bairro, favela, ou zona urbana demarcada -,é possível encontrar ambos os extremos 4 . Até onde foi possível verificar, os mercados mais competitivos e fragmentados observados pelos pesquisadores são aqueles compostos por "microtraficantes" nômades em áreas urbanizadas, como a Cracolândia, em São Paulo5. A triste realidade desses casos - revendedores individuais autônomos, vivendo à beira da extinção, operando com margens de lucro ínfimas e incapazes de gerar qualquer superávit para investir em estoques, armamento, funcionários etc. - na verdade aproxima-se das características de mercados competitivos, uma vez que não há participante capaz de se expandir e ganhar a fatia dominada por um concorrente. No outro extremo, no Rio, os donos das empresas de tráfico desfrutam de um verdadeiro monopólio local na grande maioria dos casos:é impensável um novo concorrente surgir dentro de um morro já dominado. Ademais, de uma perspectiva de concentração de mercado, esses monopólios permanecem relativamente estáveis com o passar do tempo, pois mesmo quando um dono é substituído por outro (seja da mesma facção ou de outra), o controle do comércio local conserva-se nas mãos do novo chefe.

O intervalo de concentrações de mercados de drogas observado nas nove comunidades estudadas ${ }^{6}$ foi mais estreito, ocupando uma faixa intermediária da escala, como mostra a Figura 1. Todos os casos observados tiveram um nível mínimo de concentração, que os posiciona à direita do exemploverdadeiramente excepcional do "microtráfico". Na outra ponta da escala, os mercados locais de drogas mais concentrados aproximaram-se do grau de monopólio verificado no Rio, pelo menos num corte transversal temporal.Agrande diferença está na estabilidade ao longo do tempo dos monopólios locais cariocas, que por sua vez é um fator dos aspectos estruturais e comportamentais que serão discutidos mais à frente. O "limite superior" do intervalo observado está representado por uma linha pontilhada, para enfatizar a sua qualidade porosa.
[4] Para algumas finalidades de análise, é útil pensar num nível de concentração agregado, que abranja uma cidade inteira. Numa escala desse tipo, nem mesmo o caso do Rio pode-se considerar um monopólio puro, mas sim oligopólios em concorrência. Mais interessante que o nível médio de concentração no âmbito da cidade, todavia, é a variação dentro da cidade entre os mercados locais de drogas. Essa variação será discutida adiante em mais detalhes.

[5] Ver Mingardi, G. "As drogas ilícitas em São Paulo". Revista Ilanud, São Paulo: Instituto Latino-Americano das Nações Unidas para a Prevenção do Delito e Tratamento do Delinqüente, 2001.

[6] Visitei seis das nove comunidades. Nos outros três casos, conversei com traficantes e ex-traficantes das comunidades em locais neutros. Para manter o anonimato dos entrevistados, identifico as comunidades como $\mathrm{RC}$, SP e POA, de 1 a 3 ( $\mathrm{RC}$,, $\mathrm{SP}_{3}$, $\mathrm{POA} 2$, por exemplo). 
Concentração dos mercados locais de drogas

$\begin{aligned} & \text { Fragmentado } \\ & \text { (concorrência perfeita) }\end{aligned}$
$\begin{aligned} & \text { "Microtráfico" } \\ & \text { (áreas urbanas fora de favelas) }\end{aligned}$

[7] O caso do "microtráfico" não está incluído aqui porque a maioria das variáveis não se lhe aplica.
Os mercados de drogas são constituídos, está claro, por "empresas" de tráfico, as quais tendem a adotar estruturas, estratégias e práticas que refletem a posição de mercado em que se encontram. Em geral, quanto mais concentrado o mercado, mais organizadas as empresas que o compõem. A expressão "crime organizado" é utilizada com tanta freqüência e em contextos tão variados queo seu significado deixou de seróbvio há muito tempo. Para fins de esclarecimento, apresento uma série de variáveis do âmbito empresarial que, juntas, captam as diferenças observadas entre as empresas menos organizadas de mercados mais fragmentados e as mais organizadas dos mercados mais concentrados. Isso está representado na parte superior da Figura 2: da esquerda para a direita, as colunas representam níveis crescentes de organização, em que o nível "Baixo" corresponde a uma boca minimamente organizada em uma área de favela 7 ; e "Alto", ao fenômeno como é verificado apenas no caso das facções do Rio de Janeiro. Para facilitar a exposição, as variáveis foram divididas em três grupos, que representam os aspectos empresariais, comunitários e militares da estrutura e do comportamento da empresa.A parte de baixo sobrepõese à escala do mercado de drogas da Figura 1 e informa os níveis observados de concentração/organização nas comunidades do estudo. Antes de explicar os resultados, discutirei rapidamente as variáveis componentes e a sua classificação.

\section{ASPECTOS EMPRESARIAIS}

Número de empresas e tipo de concorrência

Por definição, nos mercados altamente fragmentados, há inúmeras empresas pequenas operando em concorrência entre si. Essa concorrência, contudo, é restrita por alguns fatores significativos. A nãopadronização do produto e a falta de contratos e mecanismos legais para a resolução de conflitos propiciam incentivos aos traficantes para que estabeleçam sua reputação entre os clientes com base na qualidade e honestidade, em vez de provocar uma concorrência anônima baseada exclusivamente no preço, como a que rege nos mercados exclusivamente competitivos. Da mesma forma, a ausência generali- 


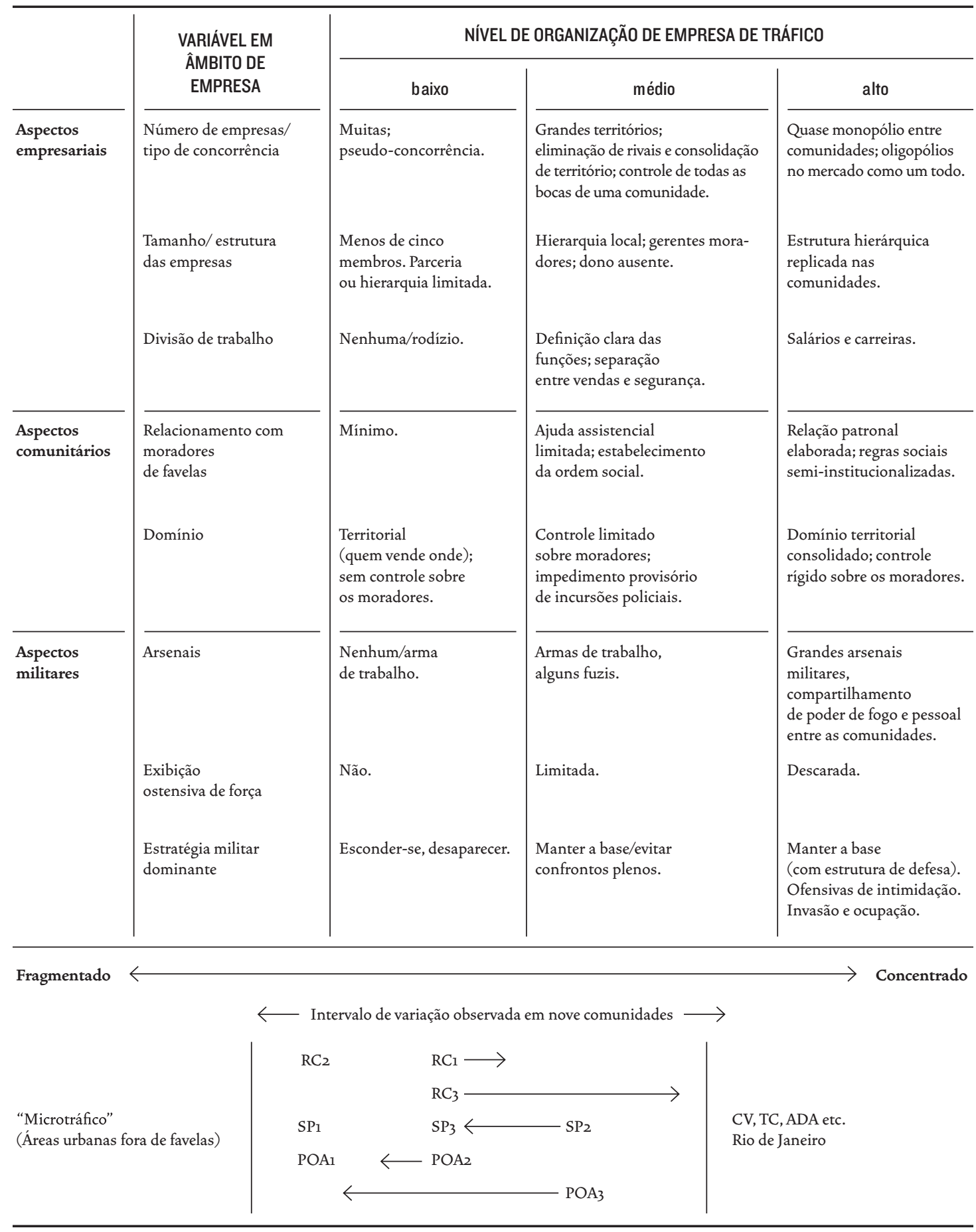

zada da polícia nas favelas e áreas de periferia possibilita que os traficantes implantem pontos fixos de venda (as bocas), dos quais são até certo ponto proprietários. O número de bocas independentes e o tamanho da área associada a cada uma (o território) são indicadores 
[8] Os mercados de drogas não são os únicos com essa característica. Qualquer um que visite os "camelódromos" do Brasil reconhecerá como um fenômeno corriqueiro (se compreendido de forma insuficiente) o esquema de fixação de preços entre os comerciantes informais concorrentes. úteis do nível de concentração: em uma comunidade com mercado altamente fragmentado ( $\mathrm{POAl}$ ), duas bocas são separadas por poucas centenas de metros e os territórios respectivos consistem em pouco mais que a área imediatamente adjacente à porta de cada uma delas. $\mathrm{O}$ posicionamento vulnerável dessas empresas pela exposição direta à polícia (ver abaixo) as faz evitar o conflito aberto entre si, o que confere estabilidade à demarcação dos territórios e, de forma interessante, dissuade a competição com base no preço (embora ela exista quanto a fatores menos tangíveis, como qualidade e localização):

Tipo,se eutenho um produto aquievocêtema doisquilômetros um produtobem melhor que o meu, o meu vai ter uma queda, entendeu? Mas... se o meu é seis reais, o seu não pode ser cinco. O seu tem que ser seis. Porque se o seu for cinco não tem mais conversa, aí a gente briga (Ex-traficante, 21 anos, $S_{3}$ ).

Desta forma, os mercados de drogas fragmentados exibem um grau circunscrito, embora relevante, de concorrência. ${ }^{8}$

Em mercados mais concentrados, as empresas controlam diversas bocas, todas com territórios maiores. A eliminação ou a incorporação de bocas rivais reduzem a concorrência, e, à medida que cai o número de empresas operando em uma comunidade, aumenta a capacidade das remanescentes em chegar a um acordo sobre os preços e a área das bocas que possuem, o que, por sua vez, reduz ainda mais a pressão de concorrência. No extremo, uma única empresa acaba controlando todas as bocas em uma única comunidade e impede a entrada de novos concorrentes. Essa situação foi observada em dois casos ( $\left.\mathrm{POA}_{3}, \mathrm{RC} 2\right)$, embora com duração limitada. No caso do Rio, o monopólio local não apenas é consolidado e estável, mas também faz parte de uma organização maior, que abrange toda a cidade. Muito embora cada dono usufrua um grau razoável de autonomia para dirigir sua operação conforme critérios próprios, a liderança da sua facção muitas vezes exerce influência pela participação na coordenação da definição de preços e o fornecimento de produtos. Assim, uma facção pode ser vista quase como um cartel, e o mercado da cidade, como oligopólios em concorrência.

\section{Tamanho, estrutura e divisão de trabalho das empresas}

Em mercados fragmentados, as empresas de tráfico são pequenas, constituídas por alguns poucos traficantes, normalmente subordinados a um chefe que controla o fornecimento de drogas por meio do contato com um atacadista. Os traficantes recebem comissões sobre as vendas e os níveis de rendimento são normalmente baixos e instáveis. As funções de segurança e vigilância, se existirem, são feitas em esquema de rodízio, sem funcionários especializados. 
Onde eu convivo lá na minha rua, os gurinem têmesse negócio de hierarquia. Todo mundoé meio que étudo (Morador de favela, $P O A \mathrm{I}$ ).

Em operações maiores, surge uma hierarquia interna, com moradores na função de gerentes, supervisionando as transações diárias, e os donos muitas vezes mantendo o controle de longe.

O meu cunhado não ia pro ponto de drogas, o negócio dele era por telefone e ele sóqueria saberdo dinheiro. Aíele mandava minha outra cunhada que era gerente dele geral, que ia lá, buscava o dinheiro, levava droga, buscava arma, levava arma (Moradorde favela, SP2).

Nessas empresas de organização intermediária, as funções de segurança e vendas são separadas, muito embora os funcionários possam revezar as funções, e os salários são raros.

T-Você tira a sua comissão, não tem dinheiro certo não, tem só o seu horário certo.

E-Mas o soldado que tá lá só dando cobertura, ele vai ganhar...

$T$-Aítem porcentagem em cima do dia em que ele tá lá.

(Traficante, 26 anos, $R C_{3}$ ).

No Rio, as empresas têm uma hierarquia complexa, replicada (com adaptações locais) nas diferentes comunidades. A divisão de trabalho é bem definida e descrita por títulos conhecidos por todos, como "olheiro", "vapor", "contenção", "gerente", "fiel" etc. Embora a maioria dos cargos associados às vendas de drogas continue a operar em esquema de comissão, os cargos importantes de segurança muitas vezes recebem um salário fixo:

No que ele vai vendendo, ele vai tirando lucro, não existe fixo. Se não vender nada, tu não ganha nada, se vender muito, ganha muito... Agora, os soldados, segurança tem um preço, assim, fixo. Você vai ganhar duzentos por semana, trezentos, quatrocentos (Morador com conhecimento sobre tráfico, de uma favela dominada pelo CV, Rio de Janeiro)?

A estabilidade duradoura dos monopólios locais e a consolidação da divisão de trabalho hierárquica geraram expectativas relativamente confiáveis de ascensão na carreira (ainda mais atraentes pela alta taxa de rotatividade): "Nego, na boca, começa como vapor e chega a gerente". ${ }^{10}$

[9] Extraído das entrevistas realizadas por Dowdney para Crianças do tráfico (op. cit.). O entrevistado é lá identificado como "Informante 1 ", embora esse trecho da entrevista não apareça no livro.

[10] Trecho de entrevista com traficante do Rio de Janeiro, extraído de Soares, L. E., Bill, M.V. e Athayde, C. Cabeça de porco. Rio de Janeiro: Objetiva, 2005, p. 257. 
[11] Dados de Rivero, P. “O mercado ilegal de armas de fogo na cidade do Rio de Janeiro" ". In: Fernandes, R. C., op. cit. Para cálculos e mais detalhes, ver Lessing, "Demanda”, op.cit.

[12] "Por um fuzil, que há três anos pagavam $\mathrm{R} \$ 10$ mil, agora chegam a desembolsar R $\$ 40$ mil." Delegado Titular da Coordenadoria de Recursos Especiais da Policia Civil do Rio de Janeiro (CORE), citado em "Desvio de munição abastece arsenal do tráfico nas favelas", Rio de Janeiro: G1, 17/11/2007.

[13] Soares, Bill e Athayde, op. cit., p. 255.

\section{ASPECTOS MILITARES}

Arsenais

As empresas menores não têm capital para obter um grande arsenal, tampouco homens para utilizá-lo de forma efetiva. Nas empresas menores, cada membro arranja a própria arma, enquanto empresas um pouco maiores fornecem uma arma de trabalho, que se revezam para usá-la. Em um caso como no outro, o mais provável é que a arma seja de cano curto e mantida encoberta sob a roupa. Os arsenais maiores surgem somente quando as empresas crescem e geram um superávit suficiente para o investimento em armas mais pesadas. A migração para fuzis automáticos é importante em vários aspectos. Primeiro, o suprimento desse tipo de arma é limitado e tentar obtê-las já é, em si, arriscado. Os preços são muito mais altos evoláteis que os das armas de cano curto:em 2005 estimava-se que cada fuzil adquirido correspondesse em preço a desde quatro a trinta revólveres ou pistolas ${ }^{11}$, e o preço pode ter subido ainda mais desde então $0^{12}$. Além disso, essas armas são difíceis ou impossíveis de se esconder quando portadas, nem podem ser utilizadas de forma discreta; logo, associam-se com estratégias de conflito mais intensas e francas, a ser examinadas abaixo. Mesmo assim, na amostra observada, a presença de fuzis automáticos foi relatada em dois terços das comunidades estudadas. Isso sugere que existam mercados para tais armas fora do Rio, e que o fator diferencial relaciona-se mais à demanda do que ao fornecimento. No caso da empresa mais organizada $\left(R_{3}\right)$, foi relatado um arsenal militar significativo. É interessante observar que esse caso confirma a suposição de Soares de que estoques de armas são um tipo de "capital imobilizado", que, pela lógica da maximização do lucro, implica uma busca pela "expansão de seu uso"13:

O armamento mais pesado fica com a questão do tráfico, né? E tem feito um estoque, assim, meio que um almoxarifado, assim, pras ações [...] fuzil, granada, metralhadora, fica como um estoque ali. [...] Ai, se eu tenho um grupo de assalto e quero fazer um assalto grande aí vejo que minhas armas não estão suficiente, eu posso ir até você e solicitar as armas. Aí a gente faz a operação, devolve a arma pra você e uma quantia pela arma, né, que você cedeu (Traficante, 26 anos, $R C_{3}$ ).

Se esse depoimento for preciso, podemos concluir que algumas empresas de drogas fora do Rio podem manter (e de fato mantêm) arsenais que incluem armamentos de classe militar que se supõem que sejam utilizados exclusivamente pelas facções cariocas. Ainda assim, os arsenais do tráfico do Rio são de uma ordem de magnitude à parte. A polícia apreendeu minas terrestres, armamentos antiaéreos, bazucas, metralhadoras calibres 30 e 50, bem como um amplo 
sortimento de armas automáticas, que inclui alguns dos modelos mais avançados tecnologicamente do mundo. Se pressupusermos que os gerentes de armas dispensem a máxima atenção e cuidado com os modelos taticamente mais importantes, a amostra de armas apreendidas na verdade pode subestimar o verdadeiro poder de fogo das facções. Além disso, as facções do Rio investiram em equipamentos avançados de comunicação e técnicas de mapeamento, $e$ chegaram a conseguir uniformes de polícia e a usá-los como uma tática bem-sucedida contra civis e rivais.

\section{Estratégia militar e exibição ostensiva de armas}

Por "estratégia militar", refiro-me à resposta típica ou mais comum a situações em que um confronto com a polícia torna-se inevitável. Claro, praticamente todos os traficantes tentarão, como primeiro recurso, subornar a polícia. Quando se considera que o comércio de drogas é onipresente, enquanto as apreensões de drogas, sejam no Rio ou em outras cidades, são eventos dignos de nota, fica claro que subornar a polícia é o modus operandi cotidiano do tráfico. Contudo, os acordos de suborno podem ser rompidos ou não estabelecidos por diversos motivos: lucros insuficientes ou inexistentes, rodízio de policiais, maior investigação pela mídia etc. Quando a situação se complica ("quando o bicho pega"), o que faz a empresa de tráfico?

Os funcionários de empresas menores, que normalmente não geram lucros suficientes para comprar os policiais no primeiro lugar, baseiam a sua estratégia de sobrevivência na invisibilidade e na mobilidade. Eles tentam escapar das investigações policiais e manter o anonimato nas comunidades em que operam. Por adotar essa estratégia, eles dificilmente utilizam armas maiores que revólveres, que em geral levam escondidos. Se descobertos e confrontados, a reação mais provável é a fuga, o que pode significar desaparecer temporariamente da comunidade em que a empresa mantém o seu território.

Operações maiores, com mais funcionários e arsenais mais bem equipados, são mais difíceis de serem disfarçadas. Ao mesmo tempo, têm mais chances de gerar lucros suficientes para viabilizar um esquema de suborno sistemático. Essas empresas empregam soldados armados de forma ostensiva e exercem uma forma de domínio territorial. Quando os acordos de suborno são rompidos, tais grupos têm mais chances de manter a sua base e recorrer à violência armada contra as forças policiais, sobretudo nas situações de choques limitados e luta pela definição dos territórios. Evidentemente nenhuma empresa opta pelo confronto maciço, em um ataque policial, se houver uma rota de fuga disponível, e, entre os casos observados, mesmo os grupos mais bem armados e protegidos temem ser expulsos por uma invasão policial: 
[14] OGloboOnline,14/06/2007. Ver também: "A guerra do Rio: durante tiroteios, quatro pessoas morreram $e$ criança com uniforme de escola foi baleada", O Globo, 15/06/2007.

[15] "Alemão: faltam policiais para vencero tráfico",OGlobo, 27/05/2007
A gente sempre compra arma, mas a gente sabe que se a polícia quiser entrarmesmo a gente não vaiter condições de... enfrentamento. Agente vai ter que enfrentar, mas a gente sabe que não vai poder, né? Porque se ela se preparar, ela vem de uma forma que, por mais que tem rapaziada, não tem a quantia que a polícia tem. Tem colete lá dentro, mas não tem pra todo mundo. Por isso que a gente tenta o mínimo confronto com a polícia (Traficante, 26 anos, $R C_{3}$ ).

Comparemos esse tipo de sentimento com o das forças do CV, no Complexo do Alemão, em meio a uma das maiores operações de ocupação já feitas pelas forças de segurança no Rio:

Indiferentes à presença de integrantes da Força Nacional de Segurança (FNS), [...] bandidos circularam carregando fuzis e pistolas [...] levantavam as armas e as apontavam para os soldados da FNS. Em conversas por meio de radiotransmissores, eles debochavam da força de ocupação, desafiando para um confronto dentro da favela. ${ }^{14}$

No final, a força de ocupação composta por mil policiais e tropas de choque equipadas com veículos blindados, entre outros, não conseguiu expulsar o CV da sua base fortificada no Alemão, comunidade que ganhou o preciso título de "a inexpugnável fortaleza do tráfico"15. O famigerado "manual de guerra" do CV (Figura 3), descoberto pela polícia durante a invasão, é testemunha eloqüente da condição humilde dos seus membros tanto quanto da orientação estratégica de "manter a base" contra a carga total da força militar do Estado.

\section{Figura 3}

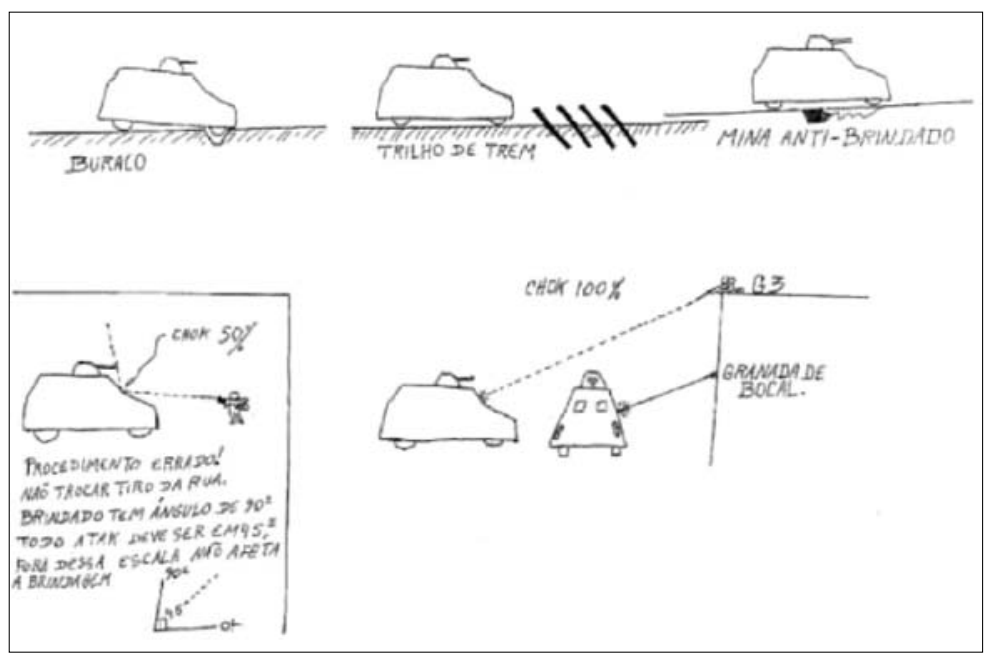


Além disso, e em aguda oposição ao comportamento de empresas de tráfico de outras cidades, as facções cariocas muitas vezes optam pela ofensiva e fazem ataquesfora de seus territórios. O tipo mais comum de ação ofensiva é a invasão e tomada de uma favela controlada por uma facção rival, um feito que por si só evidencia o poder coercitivo dessas empresas. Porém, talvez ainda mais ameaçador seja o fenômeno dos ataques simbólicos a representações do poder estadual (como metralhar o Palácio do Governador) e as "táticas de terror" na cidade (como incendiar ônibus e decretar o fechamento de lojas), que visam, entre outras coisas, ao aumento da própria visibilidade desses grupos como poderes paralelos. ${ }^{16}$

\section{ASPECTOS COMUNITÁRIOS}

Há uma literatura vasta e muito rica sobre o relacionamento entre organizações criminosas e as comunidades em que operam, portanto, limitarei esta seção a alguns comentários breves. Empresas de tráfico muito pequenas não têm praticamente poder coercivo sobre os moradores fora da área da boca. Como buscam o anonimato, essas microempresas evitam estabelecer relações mais abrangentes com membros da comunidade, a menos que ocorra um problema. À medida que crescem e conseguem dominar o comércio de drogas em toda a comunidade, as empresas se envolvem em ações comunitárias. Isso inclui o estabelecimento da ordem pública:as empresas normalmente impõem e aplicam proibições de assalto, roubo, agressões, homicídios, estupros e assim por diante ${ }^{17}$. Outra possibilidade são investimentos limitados em infra-estrutura e bens públicos (campos de futebol, ruas, serviços de transporte etc.) eações assistenciais pela distribuição direta de medicamentos e cestas básicas. Essas ações assistenciais normalmente são feitas em esquema de troca de favores, no qual os moradores, dependentes das doações dos traficantes, devem cumprir a sua parte $e$ informá-los sobre atividades policiais; esconder drogas, armas e funcionários nas suas casas durante invasões da polícia; e sobretudo manter o silêncio quando interrogados pelas autoridades.

No Rio, esse envolvimento na economia local é mais completo e comum, e também pode incluir a cobrança de serviços, como fornecimento de gás e conexões piratas de TV a cabo. Uma vez que o domínio territorial é muito mais intenso, os traficantes podem impor códigos de conduta complexos e semi-institucionalizados aos moradores, como toque de recolher, restrições a visitas, entrada e saída da favela, e até mesmo quanto a tipos de roupas permitidas. As facções também dominam a vida política das comunidades, controlando as associações de moradores e fazendo barganhas clientelistas com candidatos a postos públicos municipais, estaduais e federais. ${ }^{18}$
[16] Ver Penglase, B. "The shutdown of Rio de Janeiro: the poetics of drug traficker violence". Anthropology today, v. 21, n. 5, 2005. Esse tipo de ataque foi realizado de forma explícita, na verdade "aperfeiçoado", pelo Primeiro Comando da Capital (PCC), de São Paulo. Contudo, o PCC não é, pelo menos até este momento, uma empresa de tráfico no sentido utilizado neste trabalho.

[17] O motivo da repressão ao crime é impedir conflitos dentro da comunidade, que poderiam atrair a polícia e interromper o comércio de drogas. 
[19] Dadas as limitações deste estudo, nem todas as variáveis puderam ser observadas de forma direta, ou confiável, em todas as comunidades.

\section{VARIAÇÃO DA CONCENTRAÇÃO DO MERCADO DE DROGAS:}

\section{EQUILÍBRIOS MÚLTIPLOS}

Na porção inferior da Figura 2, foram classificadas as nove comunidades estudadas com baseem uma média aproximada dos atributos individuais discutidos ${ }^{19}$. As setas indicam a movimentação ao longo da escala com o passar do tempo (concentração por meio da consolidação do território e do controle por empresas em crescimento ou fragmentação pela divisão ou eliminação de empresas maiores). Embora essa amostra seja muito pequena para fazer afirmações definitivas quanto ao nível agregado de concentração dos mercados de drogas em qualquer uma das cidades, os dados apresentados comunicam dois aspectos interessantes sobre o grau de variação da concentração. Primeiro, nas três cidades, foi observada uma ampla variedade de mercados de drogas: em São Paulo, onde todos os casos enquadramse nas faixas média e alta, os oficiais de polícia confirmaram que em outras comunidades existem empresas que detêm um controle monopolista, ou quase, do narcotráfico. Mais importante, o fato de diversas comunidades terem informado mudanças recentes na concentração do mercado local de drogas sugere que a variação não é apenas estática, mas dinâmica: o nível de concentração dos mercados de drogas varia em função do tempo. As circunstâncias do crescimento de algumas empresas e a extinção de outras tornam nítida a existência de forças que favorecem a expansão de empresas e a consolidação de mercados - que chamo de "forças aglutinantes" - , bem como "forças fragmentadoras", que impedem o crescimento de empresas além de certos limites, corroem a posição de empresas grandes, e que, com o tempo, segmentam novamente os mercados concentrados. O conjunto dessas forças produz um equilíbrio em que o nível de concentração agregado nas cidades estudadas é moderado, e a variação entre os mercados locais éalta.

\section{Forças aglutinantes}

A maioria das forças aglutinantes agindo nos mercados de tráfico pode ser resumida pelo conceito econômico de "retornos crescentes de escala". Em geral, isso significa que, quanto mais uma empresa produza, menor o custo marginal por unidade produzida, e portanto maior a margem de lucro.Alguns exemplos de retornos crescentes no caso das empresas de tráfico: os donos de grandes operações podem negociar de forma mais dura com os fornecedores; a divisão de trabalho aumenta a eficiência dos funcionários; uma força de segurança maior, e em alguns casos o domínio territorial incondicional sobre toda a comunidade, pode garantir a proteção dos consumidores e a ausência de repressão policial nas imediações da boca, aumentando o volume das vendas. 
Ao mesmo tempo em que há incentivos econômicos subjacentes para a expansão, também há oportunidades freqüentes. Operações de baixo volume de drogas saem do mercado com regularidade, seja por prisões, mudanças forçadas de local ou mortes, e deixam o território vago para as empresas vizinhas ocuparem. Enquanto isso, a demanda inelástica, a mão-de-obra barata e as altas margens de lucro geram um superávit suficiente para prover os chefes ambiciosos e perspicazes com capital para investir em expansão. As operações maiores também têm vantagens estratégicas em relação às empresas menores, que, com o tempo, aumentam as chances de sobrevivência. Por exemplo, uma organização de grande porte terá poder de fogo e efetivo maiores para se defender contra os rivais e poderá se envolver em ações de assistência social dirigidas aos moradores da favela, que em troca poderão fornecer informações, esconderijos e outras formas de ajuda.

\section{Forças fragmentadoras}

O processo de crescimento cria um dilema para as empresas de tráfico: ao aumentar o território, o tamanho do arsenal, a divisão do trabalho e a complexidade da interação com a comunidade circundante, uma empresa também aumenta sua lucratividade, força de trabalho e estabilidade. Por outro lado, à medida que a operação de um determinado chefe ganha volume, tornam-se expostas a níveis cada vez mais altos do governo e a parcelas mais abrangentes do público. Os políticos (incluem-se aqui os chefes de polícia) que possam reivindicar para si o crédito pelo desmantelamento de uma operação desse porte receberiam compensações cada vez maiores.

\section{E-Qual a maior arma que você já viu nessa comunidade?}

M-Fuzil. FAL.Meu ex-cunhado tinha um, ele era traficante, ele tinha um...

E-Ele tinha isso para quê?? Para defender a boca?

$M-E$, para defender a boca dele.... [hoje] ele tá preso, tá preso porque estava com arma do Exército. Pegaram de bode expiatório... É, aí ele caiu, e já era. Acabafuzil (Morador de favela, POAz).

Diante de um cenário com centenas de pequenas operações (caracterizadas pela extremidade esquerda da escala acima), uma empresa que cresce ao ponto de ter gerentes e arsenais com fuzis torna-se o principal alvo. Com o aumento da diferença de tamanho entre si e os concorrentes, a operação de drogas também aumenta o prêmio implícito pela sua cabeça.

E-Então não tem por que ter tanta arma [como no Rio]?

$D$-Não teria, exatamente. Arma porque, claro, eles têm que se defender... 
de ataque, de roubo, de assalto. Mas não é aquilo que élá que é aqui. Oque mais protege é o anonimato. Eles são descobertos e logo depois começa a cair (Detetive da Polícia Civil, PortoAlegre).

Um problema secundário é o organizacional. Assim como acontece com todas as empresas, à medida que uma empresa de drogas cresce, suas operações tornam-se mais complexas, e as responsabilidades de cada membro, em particular da "alta gerência", mais decisivas. Os gerentes devem supervisionar os processos de recrutamento e folha de pagamento de um quadro grande de funcionários; embalar, distribuir e monitorar o estoque de drogas; e controlar o arsenal. Os donos devem fazer os contatos pessoais necessários para garantir um fornecimento contínuo de drogas, armas e munição; manter relacionamentos com moradores e políticos locais; e negociar os subornos de oficiais de polícia. E embora seja relativamente fácil recrutar novos "soldados" entre a grande população de jovens do sexo masculino descontentes, o mesmo não se aplica a indivíduos talentosos e experientes, com habilidades de liderança no campo de batalha. Além do mais, conforme a empresa de tráfico se expande, seus estoques de armas, drogas e dinheiro vivo para despesas diárias crescem, criando mais chances para deslealdades e rupturas da hierarquia. A polícia pode almejar gerentes de nível intermediário e utilizar ameaças de prisão e morte para extrair informações e obter cooperação. Logo, um dono deve manter muito elevados o espírito de equipe e a identidade de grupo para impedir a desintegração da sua operação.

Por motivos desse tipo, um desempenho fraco da "alta gerência" pode implicar o declínio abrupto de uma empresa de drogas de grande porte. Além disso, há uma alta rotatividade de funcionários por prisão e morte, e substitutos capazes podem ser difíceis de achar no curto prazo. Dessas condições, resultam duas forças fragmentadoras. A primeira: à medida que a empresa cresce, assim como a sua demanda por gerentes habilidosos e confiáveis, a sua estabilidade pode decair, e as maiores empresas podem desmoronar com o próprio peso organizacional.A segunda:quando uma empresa grande desmorona, pode não haver um chefe (e uma equipe) suficientemente talentoso aguardando nos bastidores para entrar em cena. A concentração do mercado de drogas é portanto uma via de duas mãos: dominar um segmento do mercado não significa sustentar o controle, tampouco garante que o mercado permanecerá concentrado no futuro.

\section{Rio:umequilíbrio único}

Os resultados preliminares apresentados aqui sugerem que na maior parte das áreas urbanas brasileiras obtém-se um equilíbrio dinâmico. Em cidades tão diferentes como Porto Alegre, São Paulo e 
Recife, um padrão semelhante é observado: as empresas de tráfico bem-sucedidas expandem-se e consolidam-se até a ação da polícia (com a morte ou prisão subseqüentes dos principais chefes) levá-las ao colapso. Se não houver um grupo com a mesma capacidade e tão bem equipado, o mercado volta ao estado anterior de fragmentação.

O mercado de drogas do Rio tem mantido um alto grau de organização nos últimos 25 anos, desde que um Comando Vermelho (CV) ainda incipiente consolidou o controle sobre a maior parte das bocas da cidade. Além do mais, com algumas exceções - o advento inicial do Terceiro Comando (TC) e a rivalidade com o CV que se seguiu, a cisão da Amigos dos Amigos (ADA), bem como outras cisões e fusões de menor importância -, trata-se de um mercado de notável estabilidade. É verdade que as facções conquistam e perdem bases entre si e que recentemente perderam algumas das favelas menos lucrativas para as milícias policiais, que expulsam os traficantes e cobram uma taxa de segurança dos moradores para manter afastado o comércio de drogas. Porém, no Rio de Janeiro, o sistema como um todo tem demonstrado resiliência e o nível de concentração, agregado ou em cada comunidade, não se tem deslocado significativamente para o lado esquerdo da escala $\mathrm{a}^{20}$. Em outras palavras, tudo indica que o narcotráfico carioca exibe um equilíbrio estável, de baixa variação e com um nível muito al to de organização.

Como o mercado de drogas chegou a esse equilíbrio no Rio e por que o mesmo fenômeno não foi observado nas outras cidades? Há diversos fatores plausíveis e poucas provas sistemáticas para a avaliação da importância relativa de cada um deles. Um elemento provável, que encontra algum apoio no meu trabalho empírico, é a geografia. Muitas das favelas do Rio situam-se em morros, o que lhes proporciona uma posição de defesa quase ideal e dificulta muito as invasões policiais organizadas. Pode ser relevante o fato de que, entre as comunidades estudadas, as que têm (ou tiveram) o mercado de drogas mais estruturado ( $\mathrm{POA}_{3}$ e $\mathrm{RC} 2$ ) também situam-se em morros com acesso difícil a veículos motorizados. Mesmo assim, está claro que a geografia não é um fator decisivo. Algumas das maiores favelas cariocas foram construídas sobre manguezais aterrados, e hoje constituem fortalezas do tráfico; $\mathrm{POA} 3$, ao contrário, voltou ao estado de fragmentação depois de uma série de chefes serem presos ou mortos.

Um argumento bastante disseminado entre os oficiais de polícia de outras cidades brasileiras é o de que a polícia carioca simplesmente é mais corrupta, inepta ou ambas as coisas. Análises menos parciais enfatizam aspectos específicos da história da polícia militar carioca, que começou como guarda real da Corte e desempenhou uma função diferente das PMs de outros estados ${ }^{21}$. Uma alegação relacionada é que fatores políticos e econômicos únicos do Rio de Janeiro - sobre-
[20] Ou seja, poucas favelas testemunharam a fragmentação dos mercados locais de drogas. Uma exceção recente e importante é o caso da divisão de duas das principais favelas da Zona Sul, Vidigal e Rocinha, em zonas separadas, controladas por facções inimigas. A expulsão total do comércio de drogas e a sua substituição pelas milícias - que aconteceu até o momento apenas em favelas com mercados de tráfico menos lucrativos - não se encaixa facilmente no quadro apresentado aqui, mas é certamente um fenômeno importante a ser estudado.

[21] Ver, por exemplo, Bretas, M. "A polícia carioca no Império", Revista estudos históricos, Rio de Janeiro, vol. 12, n. 22, 1998, pp. 219-234. 
[22] Ver Amorim, C. CV e PCC, a irmandade do crime. Rio de Janeiro: Record, 2003, p. 231.

[23] Ibidem, pp.188-193.

[24] Ibidem, p. 188 .

[25] Ver: Olson, Mancur, The logic of collective action: public goods and the theory of groups. Cambridge: Harvard University Press, 1965. Também importante é a idéia do Schelling de que, para garantir a cooperação, e desfrutar dos benefícios conseqüentes, às vezes é necessário que atores "atem as suas mãos". ver: Schelling, Thomas, The strategy of conflict. Cambridge: Harvard University Press, 1960. tudo a transferência da capital para Brasília e a fusão subseqüente do Estado da Guanabara - possam ter resultado em um aparato de segurança pública especialmente fragmentado (as forças policiais também foram amalgamadas), com a conseqüente perda debilitante de status e recursos. Há ainda quem responsabilize as políticas de direitos humanos do ex-governador Leonel Brizola, que restringiu os poderes de busca e ocupação policiais, e colocou um fim definitivo às tentativas intermitentes do Estado de erradicação de favelas. Qualquer um desses fatores pode ter contribuído para a situação única do Rio, mas nenhum deles é convincente como fator decisivo.

Outro fator potencial é a história contingente do comércio de drogas no Brasil. O mercado brasileiro de cocaína cresceu rapidamente na década de 1980, acompanhando o aumento do transporte da droga desde a Colômbia até a Europa e os Estados Unidos através do Brasil. Nesse momento histórico, a maioria das cidades brasileiras não oferecia a traficantes internacionais organizações criminosas grandes o bastante e com infra-estrutura capaz de estabelecer uma rede de distribuição hierárquica (na maioria das vezes operavam com a venda a inúmeros distribuidores médios, que por sua vez abasteciam mercados locais fragmentados). O CV, ao contrário, parece ter deliberadamente procurado os traficantes internacionais, apresentando-se como uma organização criminosa capilarizada, detentora de uma rede de distribuição pronta. ${ }^{22}$

Mas essa explicação apenas nos leva de volta à questão central sobre o CV: como ele foi capaz de proporcionar uma rede de distribuição estável a atacadistas enquanto outros grupos no Rio e em outros lugares, não? No momento da explosão do consumo da cocaína, o CV era formado principalmente por assaltantes de banco, alguns que haviam fugido recentemente da prisão e outros que ainda estavam pre$\operatorname{sos}^{23}$. Quais traços do CV, como organização, lhe permitiram explorar os retornos crescentes de escala inerentes ao comércio de drogas sem se deixar abater pelas forças fragmentadoras que, em outras cidades, eventualmente derrubam os monopólios locais?

$\mathrm{O}$ CV nasceu como uma gangue de prisão e, no momento do boom de cocaína, já tinha estabelecido um grau sem precedentes de controle sobre a vida nas cadeias, não apenas na Cândido Mendes da Ilha Grande, onde surgiu, mas em múltiplas prisões no Estado do Rio de Janeiro ${ }^{24}$. O domínio do sistema penitenciário deu aos líderes presos do CV a capacidade de eficazmente ameaçar os membros livres com represálias, caso traíssem o "movimento". Tais ameaças críveis facilitaram de forma crítica a cooperação entre os membros livres, que assim puderam "superar o problema de ação coletiva" 25 , organizando um esquema de ajuda mútua durante a sua rápida expansão e consolidação do comércio de drogas carioca. Esta "face da prisão" da facção, embora mencionada com freqüência nos relatos do surgimento do $\mathrm{CV}$, é muito 
subestimada pelas avaliações contemporâneas da guerra do tráfico no Rio. Os analistas compreensivelmente debruçam-se sobre o extraordinário poder bélico acumulado pelas quadrilhas nas favelas - a "face da favela" das facções - e tendem a considerar a liderança do CV na prisão como uma espécie de relíquia. Contudo, na medida em que os donos semi-autônomos de uma facção - seja por respeito aos chefes mais antigos encarcerados, seja por medo de sofrer represálias se forem presos de novo - cooperam e coordenam ações entre si, a face da prisão permanece crucial para a manutenção do equilíbrio do mercado de drogas do Rio. Mesmo hoje, donos sob ameaça de prisão ou invasão podem contar com os colegas da mesma facção para o fornecimento de reforços ou um refúgio seguro. Esta última vantagem é particularmente importante: quando sobrepujados em número pelas forças invasoras (seja policial ou rival), os donos normalmente se refugiam em uma favela vizinha controlada pela sua faç̧ão. Lá eles se reagrupam, reúnem armas e soldados, e esperam por uma oportunidade de recuperar o território perdido. Em outras cidades, mesmo as maiores operações de drogas não têm como se comprometer com acordos cooperativos e esquemas de ajuda mútua, e conseqüentemente não dispõem dessa tática.

A face da prisão das facções cariocas também ajuda a superar os limites organizacionais impostos pela expansão. No Rio, diferentemente do que ocorre em outras cidades, a prisão ou extermínio de um dono monopolista não leva à fragmentação do mercado de drogas da comunidade. Ao contrário, ocorre a nomeação de um substituto, normalmente feita pela liderança presa da facção e quase sempre com o seu aval. Dessa forma, o domínio das penitenciárias não apenas ajuda a impedir vácuos de poder e lutas internas, como também resolve problemas de recursos humanos e recrutamento. $O$ controle das facções sobre a vida na prisão promove a socialização dos recrutas ${ }^{26}$, a transmissão de capital social entre os presos mais jovens e os mais velhos, e representa oportunidades de aprendizado para os candidatos a futuros líderes. Mesmo quando esses mecanismos não bastam para proporcionar uma sucessão tranqüila, a fragmentação dos mercados locaisé muito rara, uma vez queas lutas internas em geral resultam na ascensão de um chefe bem armado pertencente a um comando rival, que aproveita a chance para assumiro posto. ${ }^{27}$

Sem dúvida, serei acusado de exagero pela coesão interna atribuída às facções cariocas. Na realidade, lutas internas acontecem, chefes mais antigos presos são desobedecidos e assassinados, territórios são perdidos, facções rivais surgem de cisões e assim por diante. O comércio de drogas no Rio é violento e caótico, o que indica, no argumento de alguns, de que se trata de crime desorganizado. Alguns analistas enfatizam a autonomia dos donos e a falta de uma hierarquia clara entre os líderes do CV, chegando a defini-lo como uma "pseudo-organização" 28 , "totêmica" 29 e até mesmo uma "ficção"30. Considerando a maneira
[26] “Mesmo hoje, se você for a uma prisão controlada pelo $\mathrm{CV}$, às seis da tarde em ponto, todos os prisioneiros curvam suas cabeças, levantam seus punhos e cantam o nome de Rogério Lemgruber, sem falha" (Diretor de serviços sociais da Secretaria de Estado de Administração Penitenciária do Rio de Janeiro, em entrevista com o autor, em 11/06/2007).

[27] Como aconteceu na maior favela do Rio, a Rocinha, em 2004, quando a luta pelo controle entre chefes do CV terminou com a tomada do poder pelo ADA. Ver "Disputa pelo tráfico na Rocinha cresceu a partir de 2004", Folha de S. Paulo, 16/02/2006.

[28] Pimentel, R. apud Oliveira, Adriano. As peças e os mecanismos do fenômeno tráfico de drogas e do crime organizado. Recife: tese de doutorado, Departamento de Ciências Políticas, Universidade Federal de Pernambuco, 2006 .

[29] Soares, E., apud ibidem.

[30] Oliveira, op.cit. 
[31] Extraído das entrevistas de campo de Dowdney (Crianças do tráfico, op. cit.). No original, o primeiro parágrafo vem depois do segundo, como resposta a uma pergunta sobre o porquê da realização da reunião. Inverti os dois parágrafos para fins de clareza. como a mídia demoniza e deifica o $\mathrm{CV}$, tais corretivos podem ser úteis. Porém, eles obnubilam justamente a maneira pela qual a face da prisão do CV (que não há quem afirme ser ficção) de fato afeta o comportamento dos donos. A comparação apropriada, afinal, nãoé com um exército de guerrilha, nem mesmo com a hierarquia estrita dentro de cada operação do narcotráfico, mas sim com uma situação contrafactual em que os donos mantenham sua "identidade totêmica" como membros do $\mathrm{CV}$, mas a face da prisão deixe de existir (digamos que o governo decidisse exterminar sumariamente toda a população carcerária).Consideremos as seguintes observações de um ex-chefe do CV sobre a função da "referência", um chefe recém-liberado, indicado pela liderança encarcerada para coordenar as ações dos donos:

Teve uma época no Comando Vermelho que um tava se estranhando como outro... um ficava com inveja do outro, um prendia a boca do outro. Então, tudo é desenrolado dentro da cadeia. Então, a pessoa que está lá dentro da cadeia... que é responsável de organizar tudo lá dentro, ele faz a reunião e bate o martelo e passa pra essa pessoa aquifora que hoje... é a última palaura do Comando Vermelho.

Então o que acontece? Tudo que acontece aqui fora o pessoal da cadeia tá sabendo. [...] Teve uma reunião há quatro meses atrás, onde chamou todos os donos de todas as áreas do Rio de Janeiro, do Comando Vermelho, onde [a "referência"] bateu o martelo e disse aqui que amigo que é amigo tem que se respeitar um ao outro... E teve lá todo mundo, ele bateu o martelo e agora hoje as coisas estão organizadas. Hoje qualquercaô que tem, qualquer brigalhada que tem, qualquer guerra que tem, assim, passa por ele, pra ele avaliar o que que écerto e o que é errado, para ele poder passar pro pessoal lá dentro. ${ }^{31}$

É plausível pensar que as coisas teriam ficado "organizadas" após essa reunião se a situação contrafactual fosseverdadeira, ou seja, se a liderança da prisão tivesse sido eliminada, e a "referência" não tivesse nada para reforçarà sua advertência além de um martelo? Eu diria que não, que a cooperação operacional entre chefes de quadrilhas é por natureza extremamente frágil, e depende de mecanismos que efetivamente punem e assim desestimulam - a traição ou abandono de compromissos. $\mathrm{O}$ controle sobre a vida carcerária é um mecanismo por excelência.

\section{CONCLUSÃO}

Dequalquer ponto devista, o comércio de drogas do Rioéaltamente anômalo. Mesmo nos seus mercados locais de menor grau de concentração, observam-se atributos que não são vistos nos mercados mais concentrados de outras cidades do Brasil. Aliás, o caso do Rio não é inteiramente sui generis: os dados aqui apresentados sugerem que a mesma 
lógica de expansão, concentração e militarização do tráfico local de drogas opera em várias cidades, e que a verdadeira anomalia reside no fato de que no Rio as forças de fragmentação têm sido neutralizadas. Simplesmente não é convincente atribuir de forma integral essa anomalia a diferenças na geografia, níveis de corrupção policial e política, e contingências históricas, por mais importantes que tais fatores tenham sido. Em vez disso, devemos voltar nossa atenção ao fenômeno surpreendente - e historicamente anterior à guerra do tráfico — da dominação do sistema penitenciário carioca por coletividades criminosas.

A instituição penal é entendida, desde a época do Iluminismo, como o fundamento do aparato repressor do Estado32; a existência de grupos criminosos com poder substancial sobre ela é o pecado original da falência da segurança pública no Rio de Janeiro. Tal poder desempenhou e continua desempenhando um papel crucial no estabelecimento, nos mercados de tráfico do Rio, de um equilíbrio de alta concentração, que tem se mostrado a um só tempo tragicamente violento e frustrantemente entrincheirado. No entanto, as últimas conseqüências da perda de controle sobre o sistema penitenciário para grupos criminosos e seus efeitos corrosivos sobre a lógica e a prática da segurança pública ainda estão por ser satisfatoriamente analisados. O surgimento do PCC, a consolidação de um grau de domínio dentro do sistema penitenciário paulista ainda maior do que aquele que as facções cariocas retêm, e o uso desse domínio para orquestrar os ataques de 2006, nos indicam que os resultados anômalos observados nos mercados de drogas cariocas podem ser apenas a ponta do iceberg.

BENJAMIN LESSING é estudante de doutorado em ciencia política na University of California, Berkeley. Foi pesquisador do ISER entre 2002 e 2005.

Recebido para publicação em 24 de novembro de 2007. NOVOS ESTUDOS CEBRAP $80, \operatorname{março~} 2008$ pp. $43-62$ 